\title{
Oxidation of Some Sulfated Carbohydrates: Kinetics and Mechanism of Oxidation of Chondroitin-4-Sulfate by Alkaline Permanganate with Novel Synthesis of Coordination Biopolymer Precursor
}

\author{
Ishaq Zaafarany ${ }^{1}$, Adil Gobouri ${ }^{2} \&$ Refat Hassan ${ }^{3}$ \\ ${ }^{1}$ Chemistry Department, Faculty of Applied Sciences, Umm Al-Qura University, Makkah Al-Mukarramah, \\ Saudi Arabia Kingdom \\ ${ }^{2}$ Chemistry Department, Faculty of Science, Taif University, Taif 21995, Saudi Arabia Kingdom \\ ${ }^{3}$ Chemistry Department, Faculty of Science, Assiut University, Assiut 71516, Egypt \\ Correspondence: Ishaq Zaafarany, Chemistry Department, Faculty of Applied Sciences, Umm Al-Qura \\ University, Makkah Al-Mukarramah 13401, Saudi Arabia Kingdom. E-mail: ishaq_zaafarany@yahoo.com
}

Received: July 7, 2013 Accepted: July 26, 2013 Online Published: August 5, 2013

doi:10.5539/jmsr.v2n4p23 URL: http://dx.doi.org/10.5539/jmsr.v2n4p23

\begin{abstract}
The kinetics of oxidation of chondroitin-4-sulfate as sulfated carbohydrates by alkaline permanganate has been investigated spectrophotometrically. The oxidation reaction was found to proceed through two-distinct stages. The first stage was found to be relatively fast involving the formation of unstable green $\left[\mathrm{CS}, \mathrm{Mn}^{\mathrm{VI}} \mathrm{O}_{4}{ }^{2-}\right]$ and blue $\left[\mathrm{CS}, \mathrm{Mn}^{\mathrm{V}} \mathrm{O}_{4}{ }^{3-}\right.$ ] biopolymeric coordination intermediates at wavelengths of 610 and $730 \mathrm{~nm}$, respectively. The second stage was corresponding to a slow decomposition of such intermediates to give rise to keto-acid derivative and soluble-colloidal manganese (IV) as final oxidation products. The oxidation reaction was found to be base-catalyzed. The kinetic parameters have been evaluated and a tentative oxidation reaction mechanism in good consistent with the kinetic results was suggested and discussed. Novel keto-acid derivative has been synthesized. The reaction product was characterized and identified by elemental analysis and spectral data.
\end{abstract}

Keywords: carbohydrates, chondrotin-4-sulfate, permanganate; oxidation, kinetics, mechanisms

\section{Introduction}

Although, permanganate ion is a strong oxidizing agent which has been widely used for oxidation of most organic and inorganic compounds (Stewart, 1965; Lee, 1980; Fatiadi, 1987; Dash, Patel, \& Mishra, 2009), a little attention has been focused to the oxidation of macromolecules by this oxidant. Eventhough, the kinetics of permanganate oxidation of some carbohydrates containing secondary alcoholic groups such as alginates (Hassan, 1993), pectates (Khairou \& Hassan, 2000; Khairou, 2003; Abdel-Mohsen \& Nassr, 2010), carboxymethyl cellulose (Shaker, 2001) and methyl cellulose (El-Khatib, 2002; Shaker, El-Khatib, \& Mahran, 2007) in alkaline solution has been studied by us for the first time. Unfortunately, the oxidation of sulfated carbohydrates has received a little attention (Zaafarany et al., 2010; Hassan et al., 2011). This fact may be attributed to the kinetics complexity resulting from the presence of both primary and secondary alcoholic groups along with that of sulfate moieties. Again, the suggested reaction mechanisms reported were incomplete. Some questions are still arising there such as is whether the attack of permanganate oxidant on the hydroxyl groups of C-2 and C-3 positions takes place by abstraction of either hydride ion $\left(\mathrm{H}^{-}\right)$or hydrogen atom $(\mathrm{H})$ from $\mathrm{C}-\mathrm{H}$ and $\mathrm{C}-\mathrm{OH}$ bonds, respectively.

In view of the above aspects in addition to our interest in the oxidation kinetics of carbohydrates by either this oxidant (Hassan, 1993; Khairou \& Hassan, 2000; Khairou, 2003; Abdel-Mohsen \& Nassr, 2010; Shaker, 2001; Shaker, El-Khatib, \& Mahran, 2007; El-Khatib, 2002; Hassan et al., 2011; Zaafarany et al., 2010) or by other oxidants (Hassan et al., 2010; Zaafarany et al., 2009; Hassan et al., 2011), the present work seems to be of great importance with the aims at shedding more highlights on the nature of the formed intermediates in terms of electron-transfer processes and the transition states in the rate-determining step as well as to compare the results obtained with that previously reported for oxidation of other sulfated carbohydrates by this oxidant in alkaline solutions in an attempt to elucidate a suitable reaction mechanism for oxidation in these redox systems. In addition, this work aims to synthesize a novel coordination biopolymer chelating agent. 


\section{Experimental}

\subsection{Materials}

All materials used were of analytical grade. Doubly distilled water was used in all preparations.

A stock solution of chondroitin-4-sulfate (ICN Biomedicals, Inc.) was prepared by stepwise addition of the reagent powder to doubly distilled water whilst rapidly stirring the solution to avoid the formation of aggregates, which swell with difficulty.

A stock solution of permanganate was prepared, stored and standardized as described elsewhere (Hassan, Mousa, \& El-Shatoury, 1988; Manhas, Mohammed, \& Khan, 2007; Wei \& Stewart, 1966; Stewart \& Wiberg, 1965). All other reagents were prepared by dissolving the requisite amount of the reagents in doubly distilled water.

\subsection{Kinetic Measurements}

All kinetic runs were performed under pseudo-first-order conditions where the initial concentration of (CS) was present in large excess over that of $\left[\mathrm{MnO}_{4}^{-}\right]$at a constant ionic strength of $0.1 \mathrm{~mol} \mathrm{dm}^{-3}$ in alkaline medium of pHs $\geq 12$ as described earlier (Hassan, 1993; Khairou \& Hassan,2000; Shaker, 2001; Khairou, 2003; Shaker, El-Khatib, \& Mahran, 2007; Dash, Patel, \& Mishra, 2009; Abdel-Mohsen \& Nassr, 2010). The kinetic measurements were performed by recording either the decrease or increase in absorbance of permanganate ion at wavelengths of 525 and $610 \mathrm{~nm}$, respectively.

The absorbance measurements were made in a thermostated cell compartment at the desired temperature within $\pm 0.05{ }^{\circ} \mathrm{C}$ on a Shimadzu UV-2101/3101 PC automatic scanning double beam spectrophotometer fitted with a wavelength program controller using cells of pathlength $1.0 \mathrm{~cm}$.

Some experimental runs were performed in nitrogen atmosphere in order to check the role of oxygen on the oxidation of the aldehyde which was formed during the oxidation of the primary alcohols to its corresponding acid-form.

\section{Results}

\subsection{Spectral Changes}

The spectral changes during the progress of the oxidation reaction are shown in Figure 1.

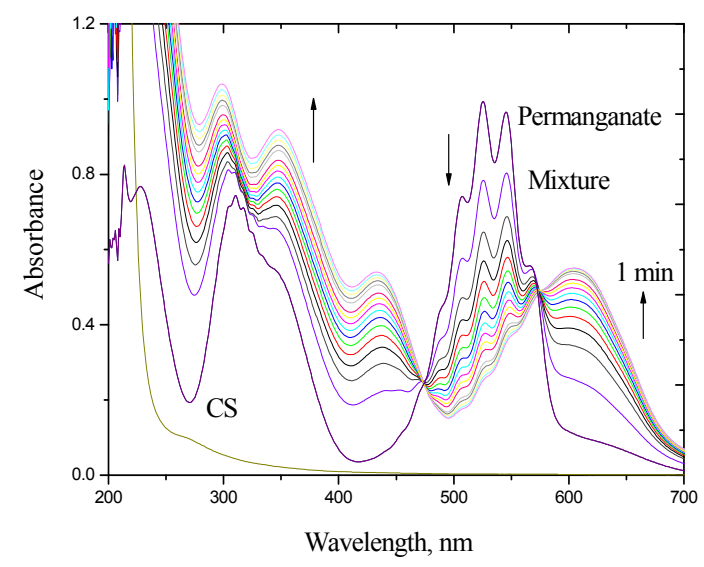

(a)

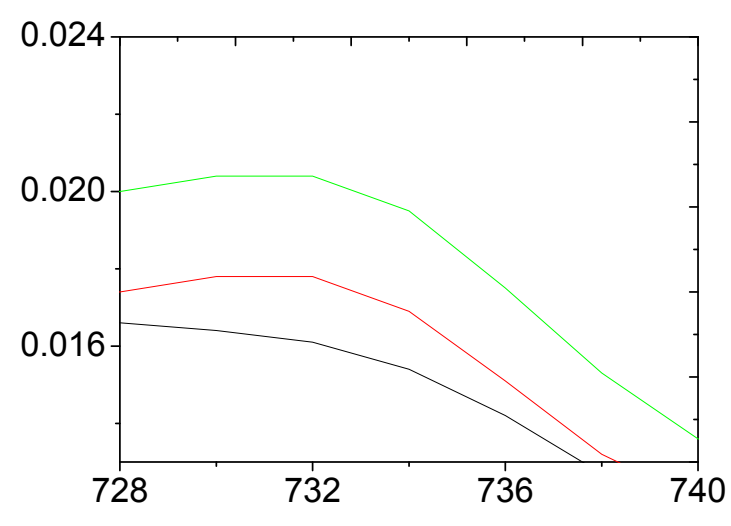

(b)

Figure 1. Spectral changes $(200-800 \mathrm{~nm})$ of chondroitin-4-sulfate by alkaline permanganate. $\left[\mathrm{MnO}_{4}^{-}\right]=4 \times 10^{-4}$, $[\mathrm{CS}]=5.5 \times 10^{-3},\left[\mathrm{OH}^{-}\right]=0.05, \mathrm{I}=0.1 \mathrm{~mol} \mathrm{dm}^{-3}$ at $25^{\circ} \mathrm{C}$. a) wavelength : $200-700 \mathrm{~nm}$ (scanning time intervals $=$ $1.0 \mathrm{~min}$ ); b) wavelength: $700-750 \mathrm{~nm}\left[\mathrm{MnO}_{4}^{-}\right]=4 \times 10^{-4}$, [CS $]=4.5 \times 10^{-4},\left[\mathrm{OH}^{-}\right]=0.01$ at $1025^{\circ} \mathrm{C}$ (scanning time intervals $=30 \mathrm{sec}$ )

\subsection{Stoichiometry}

It is important to determine the stoichiometry of this redox reaction since the present kinetics seem to be rather complex owing to the formation of transient green $\mathrm{Mn}(\mathrm{VI})$ and/or blue $\mathrm{Mn}(\mathrm{V})$ unstable intermediates. It may be difficult to determine the stoichiometric molar ratio at $\mathrm{pHs}<11$ due to the disproportionation of the formed 
manganate (VI) ion which its presence depends on the $\mathrm{pH}$ of the medium and time of measurements (Dash, Patel, \& Mishra, 2009).

Reaction mixtures containing different ratios of reactants were mixed in the presence $0.1 \mathrm{~mol} \mathrm{dm}^{-3} \mathrm{NaOH}$ and equilibrated at room temperature for about $24 \mathrm{~h}$. Estimation of unreacted $\left[\mathrm{MnO}_{4}^{-}\right]$showed that the stoichiometric ratio of $\left(\left[\mathrm{MnO}_{4}{ }^{-}\right]_{\text {consumed }} /[\mathrm{CS}]_{0}\right)$ was $2.7 \pm 0.1 \mathrm{~mol}$. This result conforms to the following stoichiometric equation,

$$
3\left(\mathrm{C}_{14} \mathrm{H}_{21} \mathrm{NO}_{14} \mathrm{~S}\right)_{\mathrm{n}}^{-}+8 \mathrm{MnO}_{4}{ }^{-}=3\left(\mathrm{C}_{14} \mathrm{H}_{15} \mathrm{NO}_{15} \mathrm{~S}\right)^{-}{ }_{\mathrm{n}}+8 \mathrm{MnO}_{2}+8 \mathrm{OH}^{-}+5 \mathrm{H}_{2} \mathrm{O}
$$

where $\left(\mathrm{C}_{14} \mathrm{H}_{21} \mathrm{NO}_{14} \mathrm{~S}\right)^{-}$and $\left(\mathrm{C}_{14} \mathrm{H}_{15} \mathrm{NO}_{15} \mathrm{~S}\right)^{-}$represent the $\mathrm{CS}$ and the corresponding diketo-acid derivative. The oxidation product was found to be the same in either the presence or absence of nitrogen atmosphere indicating that the oxidation of the formed aldehyde occurs by permanganate ion oxidant rather than by the dissolved oxygen.

The oxidation product was separated and identified by the spectral data and elemental analysis (Hassan \& Abd-Allah, 1992; Hassan, Abd-Allah, \& El-Zohry, 1993; Hassan, 1993; Khairou \& Hassan, 2000; Shaker, 2001; Khairou, 2003; Shaker, El-Khatib, \& Mahran, 2007; Dash, Patel, \& Mishra, 2009; Abdel-Mohsen \& Nassr, 2010). The diketo-derivative was characterized by the formation of 2,4-dinitrophenyl hydrazone and dioxime derivatives as well as by the IR spectral bands observed at $1760-1730 \mathrm{~cm}^{-1}$ that characterized to the carbonyl group of $\alpha$-diketones (Pretch, Clerc, Seibl, \& Simon, 1983). The disappearance of the absorption band of the OH group in the IR spectra of the products indicated the complete oxidation of $\mathrm{OH}$ groups in CS to their corresponding diketo-form. The FTIR of CS substrate and its corresponding oxidation product is shown in Figure 2 .

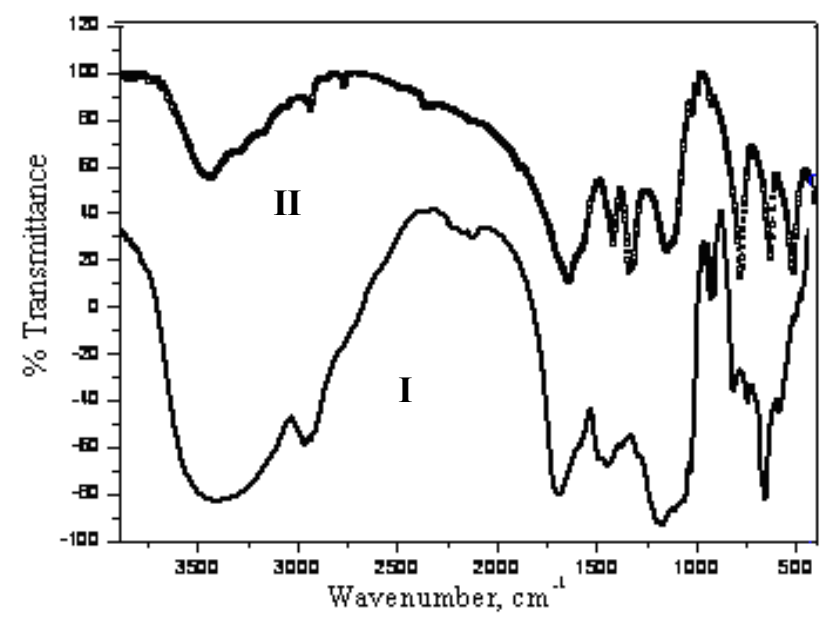

Figure 2. FTIR spectra of chondroitin-4-sulfate (I) and its diketo-acid derivative (II)

Although, the CS substrate has no capability to chelate with metal ions, the oxidation product was found to have a high tendency for chelation with some monovalent $\left(\mathrm{Ag}^{+}\right)$and divalent metal ions $\left(\mathrm{Ca}^{2+}, \mathrm{Ba}^{2+}, \mathrm{Ni}^{2+}, \mathrm{Cu}^{2+}, \mathrm{Cd}^{2+}\right.$ and $\mathrm{Pb}^{2+}$ ) through the formation of the corresponding coordination biopolymer complexes as shown in Scheme (I). The characteristics and geometrical configuration of these complexes are in progress in our laboratory. 

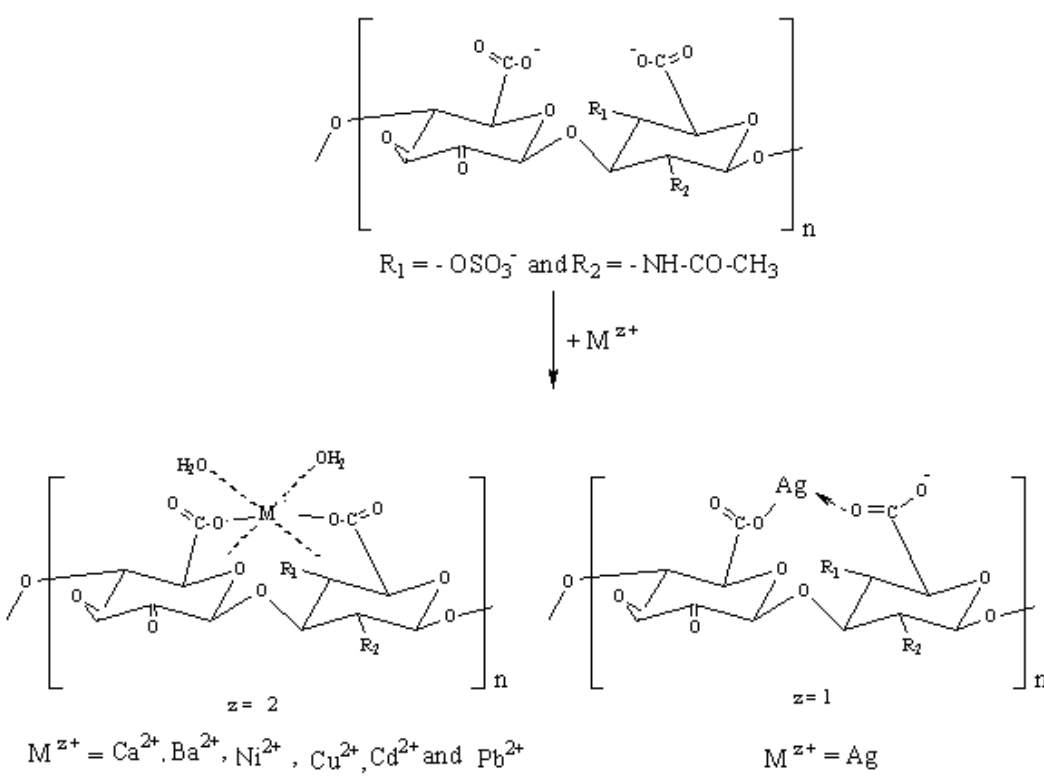

Scheme I. Speculated coordination geometry for chelation between the coordination polymer oxidation product precursor and monovalent and divalent metal ions

\subsection{Effect of $\left[\mathrm{MnO}_{4}^{-}\right]$and $[\mathrm{CS}]$ on the Reaction Rates}

As shown in Figure 1 most of the spectral features of $\mathrm{MnO}_{4}{ }^{-}$ion are displayed, but superposition of other species is apparent. There is a gradual disappearance of $\mathrm{MnO}_{4}^{-}$ion at $\lambda=525 \mathrm{~nm}$, its absorption maximum, with a simultaneous growth of new absorbance intermediates at wavelengths of $(610,435,350$ and $299 \mathrm{~nm})$. The identical pseudo-first-order rate constants, $\mathrm{k}_{\mathrm{obs}}$, obtained from the tangents of the linear portions of $\ln$ Abs. vs. time plots at either 525 or $610 \mathrm{~nm}$ (within experimental errors $\pm 4 \%$ ) indicates the reproducibility of the kinetic measurements as well as that the present reaction is first-order with respect to the permanganate concentration at the initial fast-stage. The values of the pseudo first-order rate constants for formation of some reactive coordination intermediates in oxidation of sulfated carbohydrates by alkaline permanganate are summarized in Table 1. The non-constancy for the second-order obtained from dividing the pseudo-first-order rate constants by the $[\mathrm{CS}]_{0}$ indicating the fractional order in the substrate concentration. Again, plots of $1 / \mathrm{k}_{\mathrm{obs}}$ against $1 /[\mathrm{CS}]$ were found to be linear with positive intercepts on $1 / \mathrm{k}_{\mathrm{obs}}$ axis. This linearity was found to exhibit Michaelis-Menten kinetics for formation of 1:1 intermediate complexes. A typical plot is shown in Figure 3.

Table 1. Pseudo-first order and second-order rate constants for formation of the reactive coordination intermediates in the oxidation of some sulfated carbohydrates by alkaline permanganate

$\left[\mathrm{MnO}_{4}^{-}\right]=4 \times 10^{-4},[\mathrm{~S}]=4 \times 10^{-3},\left[\mathrm{OH}^{-}\right]=5 \times 10^{-2} \mathrm{~mol} \mathrm{dm}^{-3}$ and temp. $=25^{\circ} \mathrm{C}$

\begin{tabular}{|c|c|c|c|c|c|c|}
\hline \multirow{2}{*}{ Substrate } & \multicolumn{2}{|c|}{ Rate constants } & \multirow{2}{*}{$\begin{array}{c}\begin{array}{c}\text { Deprotonation } \\
\text { constant }\end{array} \\
K, \mathrm{dm}^{3} \mathrm{~mol}^{-1}\end{array}$} & \multirow{2}{*}{$\begin{array}{c}\mathrm{I}, \\
\text { Mol dm }^{-3}\end{array}$} & \multirow{2}{*}{$\begin{array}{l}\text { Type of -OH } \\
\text { groups }\end{array}$} & \multirow[b]{2}{*}{ Ref. } \\
\hline & $\begin{array}{c}10^{3} \mathrm{k}_{\text {obs }} \\
\mathrm{s}^{-1}\end{array}$ & $\begin{array}{l}k_{l}^{\prime}, \mathrm{dm}^{3} \\
\mathrm{~mol}^{-1} \mathrm{~s}^{-1}\end{array}$ & & & & \\
\hline$k$-Carrageenan & 5.55 & 1.38 & 3.82 & 0.1 & $\begin{array}{l}\text { Primary \& } \\
\text { secondary }\end{array}$ & $\begin{array}{l}\text { Hassan } \\
\text { et al. }\end{array}$ \\
\hline$i$-Carrageenan & 0.65 & 0.16 & 2.63 & 0.5 & $\begin{array}{l}\text { Primary \& } \\
\text { secondary }\end{array}$ & $\begin{array}{c}\text { Hassan } \\
\text { et al. }\end{array}$ \\
\hline$l$-Carrageenan & 1.05 & 0.26 & 3.14 & 0.2 & $\begin{array}{l}\text { Primary \& } \\
\text { secondary }\end{array}$ & $\begin{array}{c}\text { Hassan } \\
\text { et al. }\end{array}$ \\
\hline Chondroitin-4-sulfate & 0.56 & 0.13 & 3.39 & 0.1 & $\begin{array}{l}\text { Primary \& } \\
\text { secondary }\end{array}$ & $\begin{array}{l}\text { This } \\
\text { work }\end{array}$ \\
\hline
\end{tabular}




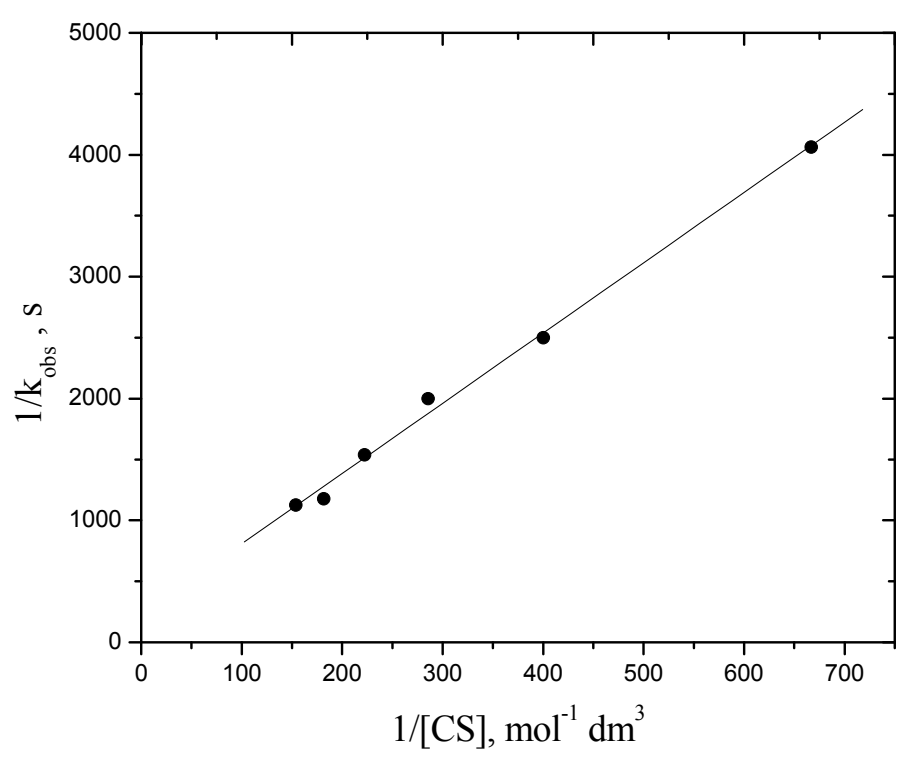

Figure 3. A typical plot of Michaelis- Menten kinetics ( $\left(1 / \mathrm{k}_{\mathrm{obs}} \mathrm{vs} .1 /[\mathrm{CS}]\right)$ for the formation of the reactive coordination intermediate complex. $\left[\mathrm{MnO}_{4}^{-}\right]=4 \times 10^{-4}$, $\left[\mathrm{OH}^{-}\right]=0.05$ and $\mathrm{I}=0.1 \mathrm{~mol} \mathrm{dm}^{-3}$ at $25^{\circ} \mathrm{C}$ and $\lambda=525 \mathrm{~nm}$

\subsection{Effect of [OH] on the Reaction Rates}

In order to elucidate a suitable reaction mechanism, the influence of alkali on the oxidation rates should be examined. The rates of reactions were found to increase with increasing the concentration of alkali. This means that the present oxidation is base-catalyzed. The order with respect to the alkali was found to be of fractional first-order ( $\log \mathrm{k}_{\mathrm{obs}}-\log \left[\mathrm{OH}^{-}\right]$plots). This means that the rate-determining step should implies at least one-reaction path involving the hydroxide ion

\subsection{Effect of Ionic Strength on the Reaction Rates}

To shed some lights on the reactive species in the rate- determining step, the influence of the ionic strength on the reaction rates was examined. Kinetic runs were performed at constant $\left[\mathrm{OH}^{-}\right]=0.05 \mathrm{~mol} \mathrm{dm}^{-3}$ as $\mathrm{NaClO}_{4}$ concentrations was increased to $0.2 \mathrm{~mol} \mathrm{dm}^{-3}$ at $25^{\circ} \mathrm{C}$. The values of $k_{o b s}$ were found to increase with increasing the ionic strength. A plot of Debye-Hückel relationship (ln $k_{o b s}$ against $\mathrm{I}^{0.5}$ plot) was found to be linear with positive slope as shown in Figure 4. The ionic strength dependence of the rate constant observed is qualitatively as expected when considering the charges involved (Hassan, 2011). 


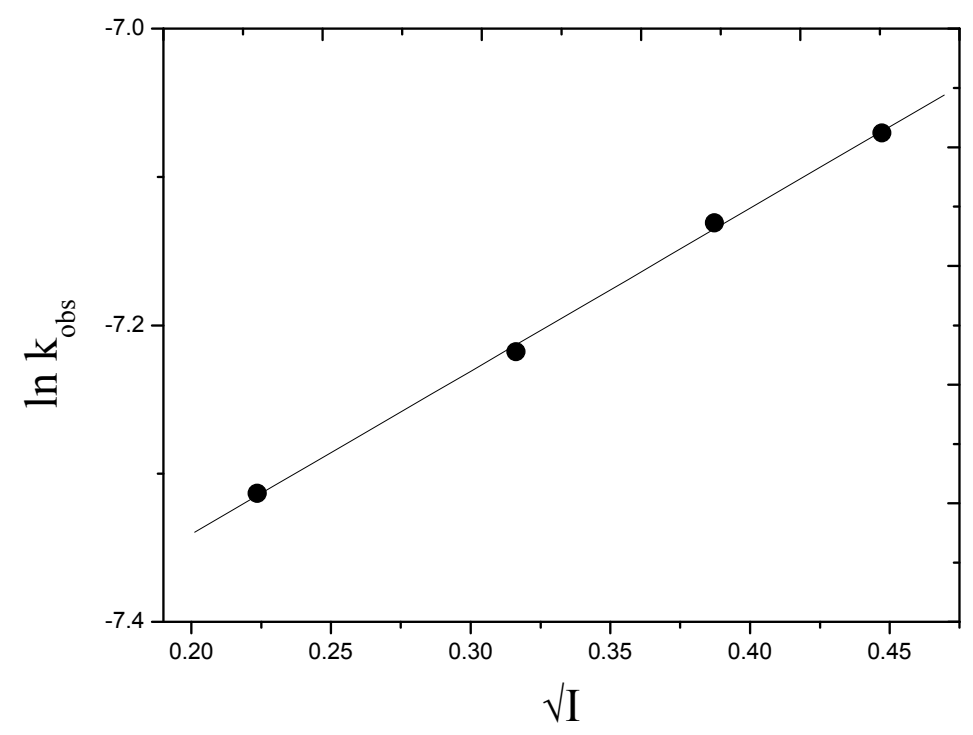

Figure 4. Debye-Huckel plot for the formation of the reactive coordination intermediate complex. $\left[\mathrm{MnO}_{4}{ }^{-}\right]=$ $4 \times 10^{-4},[\mathrm{CS}]=5.5 \times 10^{-3}$ and $\left[\mathrm{OH}^{-}\right]=0.05 \mathrm{~mol} \mathrm{dm}^{-3}$ at $25^{\circ} \mathrm{C}$ and $\lambda=525 \mathrm{~nm}$

\section{Discussion}

Chondroitin-4-sulfate has a high degree of polymerization (DP), such that it forms viscous colloidal solutions in water. The solutions are of hydrophilic sol nature, due to the presence of $\left(\mathrm{OH}^{-}\right.$and $\left.\left(\mathrm{COO}^{-}\right)\right)$moieties which has a remarkable tendency to interact with water (hydrophilic groups). In aqueous systems, orientation (swelling) of the spherical or coiled colloids into linear macromolecules can occur. This means that, an interface is formed between carbohydrate and $\mathrm{H}_{2} \mathrm{O}$ via these moieties (Shaker, 2001). Therefore, during the oxidation of $\mathrm{CS}$ by alkaline permanganate, the $\mathrm{CS}$-water interface is converted to green $\left(\mathrm{CS}-\mathrm{MnO}^{2-}{ }_{4}\right)$ sol ester intermediate which can be measured spectrophotometrically at a wavelength of $\lambda_{\max }=610 \mathrm{~nm}$.

Although, a much attention has been focused to the kinetic studies of permanganate oxidation of carbohydrates containing functional alcoholic groups in alkaline media (Hassan, 1993; Khairou \& Hassan, 2000; Shaker, 2001; Khairou, 2003; Shaker, El-Khatib, \& Mahran, 2007; Dash, Patel, \& Mishra, 2009; Abdel-Mohsen \& Nassr, 2010), a the lack of information in the literature survey on the oxidation kinetics of sulfated carbohydrates in terms of electron-transfer process is still recognized (Zaafarany et al., 2010; Hassan et al., 2011).

\subsection{Nature of Intermediates}

A wealth of information revealing the formation of manganate (VI) and/or hypomanganate (V) are presented in Figure 1. A gradual decrease in the absorption band corresponding to $\mathrm{MnO}_{4}^{-}$at $525 \mathrm{~nm}$ with a simultaneous increase in the height of the $610 \mathrm{~nm}$ peaks is observed. This behavior indicates that the permanganate oxidant reacts with $\mathrm{CS}$ via formation of detectable green $\left[\mathrm{CS}, \mathrm{Mn}^{\mathrm{VI}} \mathrm{O}_{4}{ }^{2-}\right.$ ] and/or blue $\left[\mathrm{CS}, \mathrm{Mn}^{\mathrm{V}} \mathrm{O}_{4}{ }^{3-}\right.$ ] transient coordination polysaccharide intermediates. It is well known that manganate (VI) possesses an absorption band at wavelength of $610 \mathrm{~nm}$ (Lee \& Brownridge, 1974; Hassan et al., 1993). Thus in turn, the intermediate formed at $610 \mathrm{~nm}$ may confirm the presence of manganate (VI) rather than hypomanganate (V) species. At this wavelength, the absorption of $\mathrm{MnO}_{4}{ }^{-}$is much weaker, thus the detection of $\mathrm{Mn}^{\mathrm{VI}} \mathrm{O}_{4}{ }^{2-}$ may has no difficulty (Dash, Patel, \& Mishra, 2009). But, the naked-eye observation of the change in color of the solution mixture as the reaction proceeded from purple-pink $\left(\mathrm{Mn}^{\mathrm{VII}} \mathrm{O}_{4}^{-}\right)$, to blue $\left(\mathrm{Mn}^{\mathrm{V}} \mathrm{O}_{4}{ }^{3-}\right)$, to green $\left(\mathrm{Mn}^{\mathrm{VI}} \mathrm{O}_{4}{ }^{2-}\right)$, to yellow $\left(\mathrm{Mn}^{\mathrm{IV}}\right)$, suggests the formation of the hypomanganate $(\mathrm{V})$ intermediate at the first stage of the oxidation process. The lack of detection of blue $\mathrm{Mn}(\mathrm{V})$ at around $700-730 \mathrm{~nm}$, its absorption maximum at commence of reaction may be explained by its short life-time and rapid disproportionation under our experimental conditions (Stewart \& Wiberg, 1965; Lee \& Brownridge, 1974; Simandi, Jaky, \& Schelly, 1984).

Indeed, the interconversion of $\mathrm{MnO}_{4}{ }^{-}$to both blue $\mathrm{Mn}^{\mathrm{V}} \mathrm{O}_{4}{ }^{3-}$ and green $\mathrm{Mn}^{\mathrm{VI}} \mathrm{O}_{4}{ }^{2-}$ species was manifested by the isobestic points observed at around the absorption maxima of 475 and $580 \mathrm{~nm}$ (Figure 1). Again, the yellow color which persists even after the completion of reaction confirms the formation of soluble colloidal $\mathrm{Mn}^{\mathrm{IV}}$ which may convert to brown by aging. In order to confirm the nature of the brown color, the spectrum of the 
reaction mixture was recorded at the end of reaction. The formation of an absorption band at $420 \mathrm{~nm}$ indicates that the reduced form of permanganate ion is manganese (IV).

The base-catalysis observed for formation of the intermediate complexes may suggest a fast deprotonation of CS substrate by alkali to form the more reactive alkoxide $\left(\mathrm{CS}^{-}\right)_{\mathrm{n}}$ prior to the rate-determining steps as follows,

$$
(\mathrm{CS})_{\mathrm{n}}+\mathrm{n} \mathrm{OH}^{-} \stackrel{K}{\rightleftharpoons}\left(\mathrm{CS}^{-}\right)_{\mathrm{n}}+\mathrm{n} \mathrm{H}_{2} \mathrm{O}
$$

where $K$ is the deprotonation constant. This suggestion was found to be in good agreement with the mechanisms proposed for oxidation of other aliphatic and aromatic alcohols by alkaline permanganate which gave enolate forms as reactive species via deprotonation by the alkali prior to their rate-determining steps (Jaky \& Simandi, 1981; Simandi, Jaky, \& Schelly, 1984).

In view of the above arguments and our experimental observations of the $\left[\mathrm{OH}^{-}\right]$and ionic strength dependences of the rate constants, the most suitable reaction mechanism for the initial rapid part suggests a fast deprotonation of the substrate by alkali, followed by the attack of the oxidant on the center of $\left(\mathrm{CS}^{-}\right)_{\mathrm{n}}$ to give [CS- $\mathrm{Mn}^{\mathrm{VI}} \mathrm{O}_{4}{ }^{2-}$ ] reactive coordination intermediates in the rate-determining step of the initial fast stage as follows,

$$
\mathrm{CS}^{-}+\mathrm{MnO}_{4}^{-} \stackrel{k_{1}}{\longrightarrow}\left[\mathrm{CS}-\mathrm{Mn}^{\mathrm{VI}} \mathrm{O}_{4}{ }^{2-}\right]
$$

Although, the formed $\mathrm{Mn}^{\mathrm{VI}} \mathrm{O}_{4}{ }^{2-}$ is capable to oxidize the formed alkoxide ion, the reaction is of several orders of magnitude slower than that of permanganate oxidation owing to its lower reactivity (Lee \& Sebastian, 1981; Hassan, 1993; Khairou \& Hassan, 2000; Shaker, 2001; Khairou, 2003; Shaker, El-Khatib, \& Mahran, 2007; Dash, Patel, \& Mishra, 2009; Abdel-Mohsen \& Nassr, 2010) and, hence, would not influence the kinetics of the initial stage reaction.

The change of the rate constants with the change in the substrate and hydroxide ion concentrations for formation of such detectable coordination polysaccharide intermediate at wavelengths of either 525 or $610 \mathrm{~nm}$ can be expressed as follows,

$$
\text { Rate }=-\frac{\mathrm{d}\left[\mathrm{MnO}_{4}^{-}\right.}{\mathrm{dt}}=+\frac{d\left[\mathrm{MnO}_{4}^{2-}\right]}{d t}=\frac{k K\left[\mathrm{OH}^{-}\right]\left[\mathrm{MnO}_{4}^{-}\right][\mathrm{CS}]_{T}}{1+K\left[\mathrm{OH}^{-}\right]}
$$

where $[\mathrm{CS}]_{\mathrm{T}}$ is the total analytical concentration of chondroitin-4-sulfate. When CS is present in a large excess over that of $\mathrm{MnO}_{4}^{-}$concentration, Equation (4) can be rewritten in the form:

$$
\frac{1}{\mathrm{k}_{\mathrm{obs}}}=\left(\frac{\left[O H^{-}\right]^{-1}}{k_{1} K}+\frac{1}{\mathrm{k}_{1}}\right) \frac{1}{[C S]_{T}}
$$

Equation (5) requires that plotting of $1 / \mathrm{k}_{\mathrm{obs}}$ against $1 /[\mathrm{CS}]_{\mathrm{T}}$ to be straight line passing through the origin. Unfortunately, this rate-law did not agree with the experimental observations for the appearance of positive intercepts on $1 / \mathrm{k}_{\text {obs }}$ axis as shown in Michaelis-Menten plot (Figure 3). Therefore, it may convenient to suggest the formation of transient species $\left(\mathrm{C}_{1}\right)$ prior to the formation of the reactive coordination intermediate [CS, $\left.\mathrm{Mn}^{\mathrm{VI}} \mathrm{O}_{4}{ }^{2-}\right]$ as follow

$$
\mathrm{CS}^{-}+\mathrm{MnO}_{4} \stackrel{\mathrm{K}_{1}}{\rightleftharpoons} \mathrm{C}_{1} \stackrel{k_{1}}{\longrightarrow}\left[\mathrm{CS}-\mathrm{Mn}^{\mathrm{VI}} \mathrm{O}_{4}{ }^{2-}\right]
$$

Applying the steady state approximation for the concentration of $\mathrm{C}_{1}$ transient intermediate, the change of the rate-constants with the changes of the $\left[\mathrm{OH}^{-}\right]$and $\mathrm{CS}$ concentration leads to the following rate-law equation

$$
\begin{gathered}
\frac{1}{\mathrm{k}_{\mathrm{obs}}}=\left(\frac{1+K\left[\mathrm{OH}^{-}\right]}{k_{1} K K_{1}\left[\mathrm{OH}^{-}\right]}\right) \frac{1}{[C S]_{T}}+* K^{\prime} \\
* \mathrm{~K}^{\prime}=\left[\mathrm{MnO}_{4}^{-}\right] / \mathrm{k}_{1}[\mathrm{CS}]_{\mathrm{T}}
\end{gathered}
$$

Equation (7) requires that at constant $\left[\mathrm{OH}^{-}\right]$the plots of $1 / \mathrm{k}_{\mathrm{obs}}$ against $1 /[\mathrm{CS}]_{\mathrm{T}}$ to be linear with positive intercepts on $1 / \mathrm{k}_{\mathrm{obs}}$ axis as was experimentally observed (Figure 3 ). Again, plots of $1 / k_{\text {obs }}$ versus $1 /\left[\mathrm{OH}^{-}\right]$at constant $[\mathrm{CS}]$ gave good straight lines with positive intercepts on $1 / k_{o b s}$ axis. The relatively small intercept observed in Figure 3 , may lead us to simplify Equation (7) to Equation (8), 


$$
\frac{[\mathrm{CS}]_{\mathrm{T}}}{\mathrm{k}_{\mathrm{obs}}}=\frac{1}{\mathrm{k}^{\prime}}=\left(\frac{\left[\mathrm{OH}^{-}\right]^{-1}}{\mathrm{k}_{1}^{\prime}}+\frac{1}{\mathrm{k}_{1}^{\prime \prime}}\right)
$$

where $k_{l}{ }^{\prime}$ and $k_{l}{ }^{\prime \prime}$ are the apparent rate constants $\left(k_{l}{ }^{\prime}=k_{l} K K_{l}\right.$, and $\left.k_{l}{ }^{\prime \prime}=k_{l} K_{l}\right)$ and $k^{\prime}$ is the second-order rate constant $\left(k_{o b s} /[\mathrm{CS}]\right)$.

According to Equation (8), at various temperatures the plots of [CS $] / \mathrm{k}_{\text {obs }}$ against $1 /\left[\mathrm{OH}^{-}\right]$gave good straight lines with positive intercepts on $[\mathrm{CS}] / \mathrm{k}_{\mathrm{obs}}$ axis as shown in Figure 5. The values of the apparent rate constants $\left(k_{l}{ }^{\prime}\right.$ and $\left.k_{l}^{\prime \prime}\right)$ and the deprotonation constants $\left(K=k_{l}^{\prime} / k_{l}^{\prime \prime}\right)$ were evaluated from the slopes and intercepts of such plots using the method of least-squares.

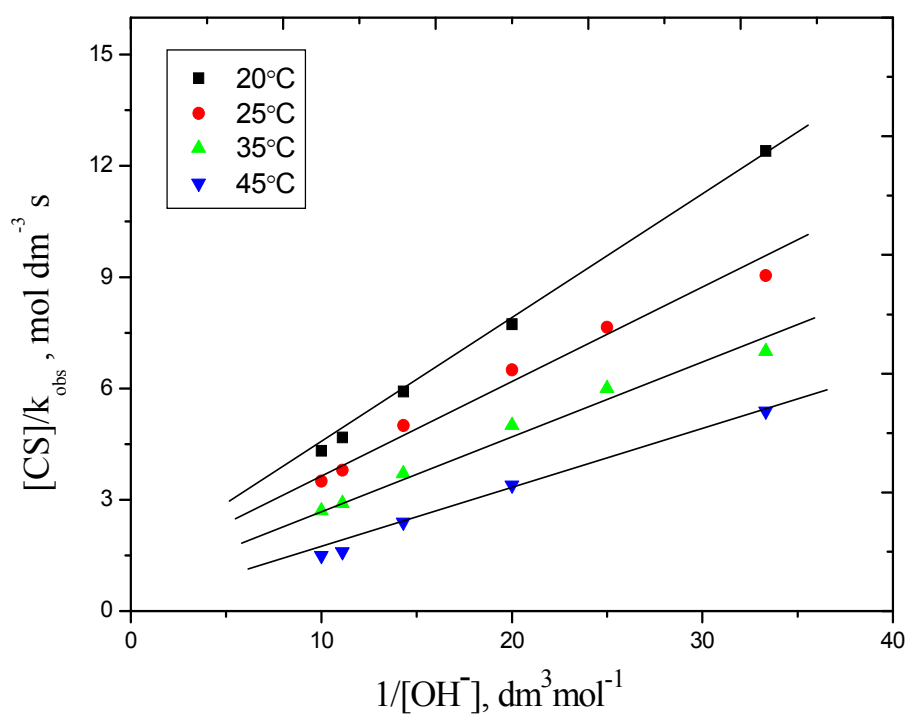

Figure 5. Plots of $[\mathrm{CS}] / \mathrm{k}_{\mathrm{obs}}$ vs. $1 /\left[\mathrm{OH}^{-}\right]$for the formation of the reactive coordination intermediate complex. $\left[\mathrm{MnO}_{4}^{-}\right]=4 \times 10^{-4},[\mathrm{CS}]=5.5 \times 10^{-3}$ and $\mathrm{I}=0.1 \mathrm{~mol} \mathrm{dm}^{-3}$ at $\lambda=525 \mathrm{~nm}$

The second-order rate constants $\left(\mathrm{k}_{\mathrm{obs}} /[\right.$ substrate $\left.]\right)$ and the protonation constants $(\mathrm{K})$ in the oxidation of some sulfated polysaccharides by this oxidant are summarized in Table 1 . The values of the deprotonation constants for the present study shown in Table 1 were found to be in the same order of magnitude to that obtained previously for oxidation of other sulfated carbohydrates by alkaline permanganate (Hassan, 1993; Khairou, \& Hassan, 2000; Shaker, 2001; Khairou, 2003; Shaker, El-Khatib, \& Mahran, 2007; Dash, Patel, \& Mishra, 2009; Abdel-Mohsen \& Nassr, 2010). This result may confirm the validity of the proposed mechanism.

Unfortunately, the values of the rate constant of the elementary reaction $\left(\mathrm{k}_{1}\right)$ could not be calculated owing to the non- availability of the formation constants $\left(\mathrm{K}_{1}\right)$ and the deprotonation constants $(\mathrm{K})$ at various temperatures. Therefore, the calculated values of $k_{1}{ }^{\prime}$ and $k_{l}{ }^{\prime \prime}$ are considered to be composite quantities of the apparent rate constants, the deprotonation constants and the formation constants, respectively. The activation parameters of the apparent rate constants $\left(k_{l}^{\prime}\right.$ and $\left.k_{l}^{\prime \prime}\right)$ and second-order rate constant $\left(k^{\prime}\right)$ were calculated from the temperature-dependence of the observed rate constants integrated equations by the method of least-squares using the Arrhenius and Eyring equations. The results along with that of other sulfated carbohydrates oxidized by alkaline permanganate are summarized in Table 2 . 
Table 2. Kinetic parameters of the apparent rate constants $\left(k_{l}^{\prime}\right.$ and $\left.k_{l}^{\prime \prime}\right)$ during formation of the reactive coordination intermediates in the oxidation of some sulfated carbohydrates by alkaline permanganate

$\left[\mathrm{MnO}_{4}^{-}\right]=4 \times 10^{-4},[\mathrm{~S}]=(4-5.5) \times 10^{-3}$ and $\mathrm{I}=(0.1-0.5) \mathrm{mol} \mathrm{dm}^{-3}$ at $\lambda=525 \mathrm{~nm}$

\begin{tabular}{|c|c|c|c|c|c|c|}
\hline \multirow{3}{*}{ CARB } & \multirow{3}{*}{$\begin{array}{c}\text { Rate } \\
\text { constant }\end{array}$} & \multicolumn{5}{|c|}{ Parameter } \\
\hline & & $\Delta S^{\ddagger}$ & $\Delta H^{\ddagger}$ & $\Delta G^{\neq}$ & $E_{a}^{\neq}$ & A \\
\hline & & $\mathrm{J} \mathrm{mol}^{-1} \mathrm{~K}^{-1}$ & $\mathrm{~kJ} \mathrm{~mol}^{-1}$ & $\mathrm{~kJ} \mathrm{~mol}^{-1}$ & $\mathrm{~kJ} \mathrm{~mol}^{-1}$ & $\mathrm{~mol}^{-1} \mathrm{~s}^{-1}$ \\
\hline \multirow{2}{*}{$\mathrm{CS}$} & $\mathrm{k}_{1}^{\prime}$ & -134.74 & 29.64 & 69.79 & 31.94 & $1.43 \times 10^{6}$ \\
\hline & $\mathrm{k}_{1} "$ & -233.96 & 3.08 & 72.80 & 5.67 & $0.1 \times 10^{2}$ \\
\hline \multirow{2}{*}{ KCAR } & $k_{1}^{\prime}$ & -148.41 & 20.13 & 64.36 & 22.63 & $3.01 \times 10^{5}$ \\
\hline & $k_{1}^{\prime \prime}$ & -220.14 & 1.97 & 67.57 & 4.44 & $0.53 \times 10^{2}$ \\
\hline \multirow{2}{*}{ ICAR } & $k_{1}^{\prime}$ & -148.32 & 25.91 & 70.11 & 24.17 & $1.56 \times 10^{7}$ \\
\hline & $k_{1}^{\prime \prime}$ & -205.77 & 11.18 & 72.45 & 13.73 & $3.21 \times 10^{4}$ \\
\hline \multirow{2}{*}{ LCAR } & $k_{1}^{\prime}$ & -149.65 & 24.17 & 68.77 & 29.06 & $5.03 \times 10^{5}$ \\
\hline & $k_{1}^{\prime \prime}$ & -213.67 & 7.91 & 71.58 & 10.43 & $0.36 \times 10^{2}$ \\
\hline
\end{tabular}

The observed large negative values of $\Delta \mathrm{S}^{\ddagger}$ (Table 2) may confirm the compactness of the coordination intermediate complex formed rather than the reactants. Again, the positive values of $\Delta H^{0}$ (Table 3) indicate the endothermic nature for the deprotonation process.

Table 3. Thermodynamic parameters of the deprotonation constants, $\mathrm{K}$, (formation) in the oxidation of some sulfated carbohydrates by alkaline permanganate. $\mathrm{CS}$ at $\mathrm{I}=0.1, \mathrm{KCAR}$ at $\mathrm{I}=0.1, \mathrm{ICAR}$ at $\mathrm{I}=0.5$ and L-CAR at $\mathrm{I}=0.2 \mathrm{~mol} \mathrm{dm}^{-3} .[\mathrm{S}]=(4-5.5) \times 10^{-3}$ and $\left[\mathrm{MnO}_{4}^{-}\right]=4 \times 10^{-4} \mathrm{~mol} \mathrm{dm}^{-3}$

\begin{tabular}{cccc}
\hline CARB & $\begin{array}{c}\Delta H^{o} \\
\mathrm{~kJ} \mathrm{~mol}^{-1}\end{array}$ & $\begin{array}{c}\Delta G_{T}^{o} \\
\mathrm{~kJ} \mathrm{~mol}^{-1}\end{array}$ & $\begin{array}{c}\Delta S_{T}^{o} \\
\mathrm{~J} \mathrm{~mol}^{-1} \mathrm{~K}^{-1}\end{array}$ \\
\hline CS & +26.62 & +99.48 & -3.03 \\
KCAR & +18.36 & -2.92 & +72.62 \\
ICAR & +14.75 & -2.69 & +57.56 \\
LCAR & +16.25 & -2.83 & +64.04 \\
\hline
\end{tabular}

Experimental error $\pm 3 \%$.

Stewart (Hassan et al., 1993) and Hassan (Hassan, 1992, 2011) reported that the values of entropy of activation tend to be more positive for reactions of outer-sphere mechanisms, whereas these values are more negative for reactions of inner-sphere types. The values of entropies of activation observed in Table 2 may indicate that the electron-transfer process is of inner-sphere nature. Again, Leffler and Grunwald have pointed out that many reactions show an isokinetic linear relationship $\Delta \mathrm{H}^{\neq}=\alpha+\beta \Delta \mathrm{S}^{\neq}$for some redox reactions which proceeding by similar mechanisms. As shown in Figure 6, a plot of $\Delta \mathrm{H}^{\neq}$against $\Delta \mathrm{S}^{\neq}$of the second-order rate constants of oxidation of various sulfated carbohydrates by alkaline permanganate was linear. This linearity may indicate that these redox systems are proceeding by similar reaction mechanisms. 


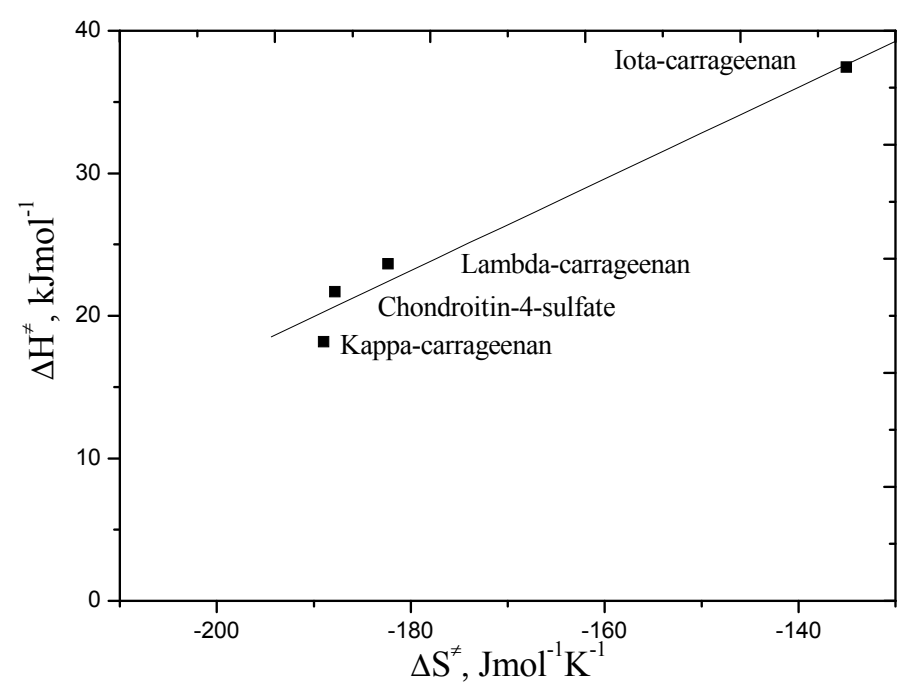

Figure 6. Isokinetic plot for the second-order rate constants, $\Delta \mathrm{H}^{\neq}$vs. $\Delta \mathrm{S}^{\neq}$, in the oxidation of some sulfated carbohydrates by alkaline permanganate

Moreover, the negative values of $\Delta \mathrm{S} \neq$ obtained (Table 4) in addition to the linearity observed in Figure 6 may be considered as evidences to support the inner-sphere nature of the electron-transfer processes.

Table 4. Activation parameters of the second-order rate constants of the formation of the coordination intermediates in the oxidation of some sulfated carbohydrates by alkaline permanganate. $\left[\mathrm{MnO}_{4}^{-}\right]=4 \times 10^{-4},[\mathrm{~S}]$ $=(4-5.5) \times 10^{-3},\left[\mathrm{OH}^{-}\right]=\left(2-5 \times 10^{-2}\right) \mathrm{mol} \mathrm{dm}^{-3}$

\begin{tabular}{ccccc}
\hline Substrate & $\begin{array}{c}\Delta H^{\ddagger} \\
\mathrm{kJ} \mathrm{mol}^{-1}\end{array}$ & $\begin{array}{c}\Delta S^{\ddagger} \\
\mathrm{J} \mathrm{mol}^{-1} \mathrm{~K}^{-1}\end{array}$ & $\begin{array}{c}\Delta G^{\ddagger} \\
\mathrm{kJ} \mathrm{mol}^{-1}\end{array}$ & Ref. \\
\cline { 2 - 5 } & \multicolumn{3}{c}{ Formation } \\
\hline$k$-Carrageenan & 18.17 & -188.99 & 72.70 & Hassan et al. \\
$i$ - Carrageenan & 37.45 & -135.06 & 77.69 & Hassan et al. \\
l- Carrageenan & 23.65 & -182.35 & 78.33 & Hassan et al. \\
Chondroitin-4-sulfate & 21.68 & -187.82 & 77.65 & This work \\
\hline
\end{tabular}

In view of the visual naked eye observations for formation of the blue hypomanganate $(\mathrm{V})$ at the commence of the oxidation process, it may possible to suggest that the transient species $\left(\mathrm{C}_{1}\right)$ is corresponding to the formation of blue $\left[\mathrm{CS}, \mathrm{Mn}^{\mathrm{V}} \mathrm{O}_{4}{ }^{3-}\right]$ which is rapidly decomposed to give the detectable reactive green coordination intermediate [CS, $\mathrm{Mn}^{\mathrm{VI}} \mathrm{O}_{4}{ }^{2-}$ ] observed at a wavelength of $610 \mathrm{~nm}$ in the rate-determining step of the first rapid stage (Hassan, 1993; Khairou \& Hassan, 2000; Shaker, 2001; Khairou, 2003; Shaker, El-Khatib, \& Mahran, 2007; Dash, Patel, \& Mishra, 2009; Abdel-Mohsen \& Nassr, 2010). This fact may be supported by the appearance of the two-isobestic points at wavelengths of 580 and $475 \mathrm{~nm}$. Again, the short relaxation time of about few seconds elapsed after the first appearance of the blue hypomanganate (V) may indicate its fast disproportionation to give $\mathrm{Mn}(\mathrm{VI})$ and $\mathrm{Mn}(\mathrm{IV})$. The concentration of $\mathrm{Mn}(\mathrm{VI})$ is built up until reaches a maximum, then it slowly decays to give rise to the final oxidation products in the second stage of oxidation.

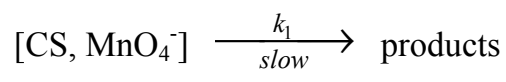

Fortunately, the keen trials for detection of hypomanganate (V), in particularly at lower temperatures and substrate concentrations, were met with success as shown in Figure 1 which shows a repeat scanning for absorbance as a function of time between 700 and $800 \mathrm{~nm}$ (time intervals is 30 seconds). As is shown in these 
scans the blue coordination polysaccharide intermediate $\left[\mathrm{CS}, \mathrm{Mn}^{\mathrm{V}} \mathrm{O}_{4}{ }^{3-}\right.$ ] that involving blue hypomanganate (V) could be detected at around $730 \mathrm{~nm}$, but its appearance is still highly unstable which its presence depends on the $\mathrm{pH}$ and the reaction conditions.

In view of the above kinetic interpretations and the experimental results, a speculated reaction mechanism may be suggested as shown in Scheme (II).

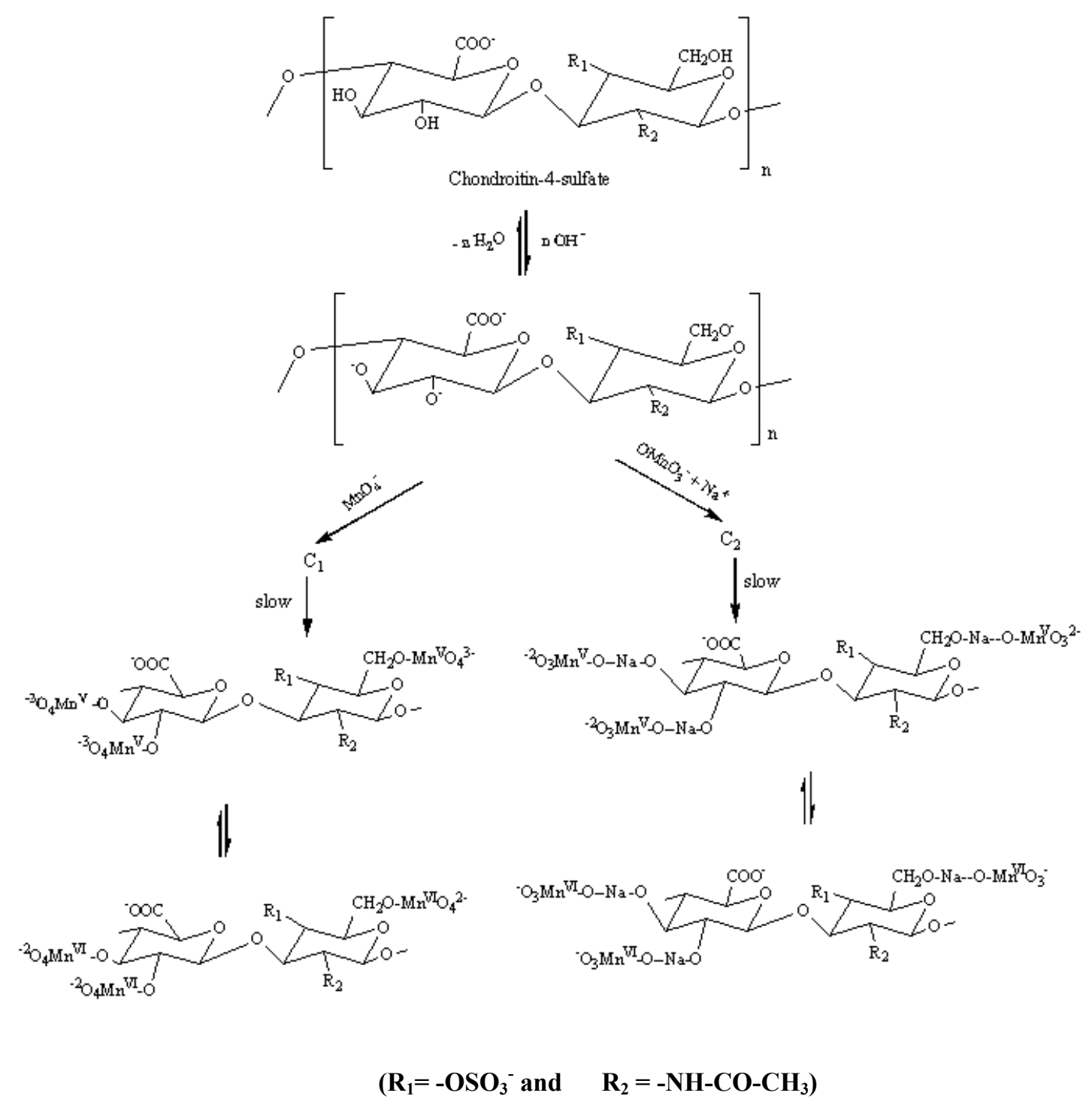

Scheme II. Mechanism of oxidation of CS by alkaline permanganate (Formation)

The first step corresponds to the removal of protons from the alcoholic group by alkali to give the reactive alkoxide form, followed by the attack of $\mathrm{MnO}_{4}{ }^{-}$oxidant to the alkoxide center which can be facilitated by the polarization of the $\mathrm{Mn}-\mathrm{O}$ bond or $\mathrm{NaMnO}_{4}$ forming the reactive transient species $\mathrm{C}_{1}$ prior to the formation of the stable [CS, $\mathrm{Mn}^{\mathrm{VI}} \mathrm{O}_{4}{ }^{2-}$. As reported elsewhere (Hassan, 1993; Khairou \& Hassan, 2000; Shaker, 2001; Khairou, 2003; Shaker, El-Khatib, \& Mahran, 2007; Dash, Patel, \& Mishra, 2009; Abdel-Mohsen \& Nassr, 2010), when green intermediate manganate (VI) builds up to maximum concentration, it commences to decompose with a simultaneous decrease in absorbance to give rise to the corresponding coordination biopolymer precursor keto-acid derivative as final oxidation product.

A speculated coordination geometrical structure for chelation between the coordination polymer precursor oxidation product and monovalent and divalent metal ions was illustrated in Scheme I. 


\section{Conclusion}

In view of the experimental results and the kinetic interpretations, it is obvious that oxidation of chondroitin-4-sulfate by alkaline permanganate leads to the formation of novel coordination biopolymer precursor. This product can be used as a chelating agent for removal of most undesired and poisonous heavy metal ions from contaminated matters or as a biocatalyst in immobilization systems. New detection of unstable intermediates involving blue hypomanganate (V) and green manganate (VI) using conventional spectrophotometer was recognized in such redox reaction.

\section{References}

Abdel-Mohsen, L., \& Nassr, E. (2010). Kinetics and mechanism of disproportionation of $\mathrm{Mn}(\mathrm{VI}) \mathrm{O}_{42}-$ induced by decomposition of intramanganato-polygalacturonate methyl ester coordination polymer precursor: Medium-substituent effects on reactivity. Carbohydr. Polym., 82, 880-886. http://dx.doi.org/10.1016/j.carbpol.2010.06.008

Dash, S., Patel, S., \& Mishra, B. K. (2009). Oxidation by permanganate: Synthetic and mechanistic Aspects. Tetrahedron, 65, 707-739. http://dx.doi.org/10.1016/j.tet.2008.10.038

El-Khatib, R. M. (2002). Spectrophotometric detection of methyl cellulose-manganate (VI) intermediate complex in the oxidation of methyl cellulose by alkaline permanganate. Carbohydr. Polym., 47, 377-385. http://dx.doi.org/10.1016/S0144-8617(01)00192-8

Fatiadi, A. J. (1987). The Classical Permanganate Ion: Still a Novel Oxidant in Organic Chemistry. Synthesis, 2 , 85-127. http://dx.doi.org/10.1055/s-1987-27859

Hassan, R. M., Alarifi, A., Fawzy, A., Zaafarany, I. A., Khairou, K. S., Ikeda, Y., \& Takagi, H. D. (2010). Acid-catalyzed oxidation of some sulfated polysaccharides: kinetics and mechanism of oxidation of kapp-carrageenan by cerium (IV) in aqueous perchlorate solutions. J. Mol. Cat., 332, 138-144. http://dx.doi.org/10.1016/j.molcata.2010.09.009

Hassan, R. M. (1992). A review on oxidation of uranium (IV) by polyvalent metal ions. A linear free-energy correlation. J. Coord. Chem., 27, 255-266. http://dx.doi.org/10.1080/00958979209407958

Hassan, R. M. (1993a). Alginate polyelectrolyte ionotropic gels. XIV. Kinetics and mechanism of formation of intermediate complex during the oxidation of alginate polysaccharide by alkaline permanganate with a spectrophotometric evidence of manganate (VI) transient species. J. Polym. Sci., Part A, 31, 51-59.

Hassan, R. M. (1993b). Alginate polyelectrolyte ionotropic gels. XVIII. Oxidation of alginate polysaccharide by potassium permanganate in alkaline solutions. kinetics of decomposition of the intermediate complex. $J$. Polym. Sci., Part A, 31, 1147-1151. http://dx.doi.org/10.1002/pola.1993.080310508

Hassan, R. M. (2011). A mechanistic approach to the kinetics of oxidation of uranium (IV) by hexachloroplatinate (IV) in aqueous perchlorate solutions. evidence of the formation of a binuclear intermediate complex. J. Phys. Chem. A, 115, 13338-13345. http://dx.doi.org/10.1021/jp204991w

Hassan, R. M., \& Abd-Allah, M. A. (1992). New coordination polymers. I. Novel synthesis of poly (vinyl alcohol) and characterization as chelating agent. J. Mat. Sci., 2, 609-611.

Hassan, R. M., Abd-Allah, M. A., \& El-Zohry, M. F.(1993). Alginate polyelectrolyte ionotropic gels. VI. Novel synthesis of diketoalginate as bipolymer precursor. J. Appl. Polym. Sci., 47, 1649-1652. http://dx.doi.org/10.1002/app.1993.070470912

Hassan, R. M., Ahmed, S. M., Fawzy, A., Abdel-Kader, D. A., Ikeda, Y., \& Takagi, H. D. (2010). Acid-catalyzed oxidation of carboxymethyl cellulose polysaccharide by chromic acid in aqueous perchlorate solutions. A kinetic study. Cat. Commun., 11, 611-615. http://dx.doi.org/10.1016/j.catcom.2010.01.006

Hassan, R. M., Fawzy, A., Alarifi, A., Ahmed, G. A., Zaafarany, I. A., \& Takagi, H. D. (2011). Base-catalyzed oxidation of some sulfated macromolecules: kinetics and mechanism of formation of intermediate complexes of short-lived manganate (VI) and/ or hypomanganate (V) during oxidation of iota- and lamba-carrageenan polysaccharides by alkaline permanganate. J. Mol. Cat. A, 335, 38-45. http://dx.doi.org/10.1016/j.molcata.2010.11.011

Hassan, R. M., Ibrahim, S. M., Zaafarany, I. A., Fawzy, A., \& Takagi, H. D. (2011). Base-catalyzed oxidation. Kinetics and mechanism of hexacyanoferrate (III) oxidation of methyl cellulose polysaccharide in alkaline solutions. J. Mol. Cat., 344, 93-98. 
Hassan, R. M., Mousa, M. A., \& El-Shatoury, S. A. (1988). Kinetics of the oxidation of uranium (IV) by permanganate ion in aqueous perchlorate media. J. Chem. Soc. Dalton Trans., 601-603. http://dx.doi.org/10.1039/dt9880000601

Jaky, M., \& Simandi, L. I. (1981). Permanganate oxidations in strongly basic solutions. React. Kinet. Catal. Lett., 18, 485. http://dx.doi.org/10.1007/BF02065647

Khairou, K. S. (2003). Kinetics and mechanism of decomposition of intermediate complex during oxidation of pectate polysaccharide by potassium permanganate in alkaline solutions. Inter. J. Chem. Kinet., 35, 67-72. http://dx.doi.org/10.1002/kin.10100

Khairou, K. S., \& Hassan, R. M. (2000). Pectate polyelectrolyte ionotropic gels. I. Kinetics and mechanism of formation of manganate(VI)-pectate intermediate complex during oxidation of pectate polysaccharide by alkaline permanganate. Eur. Polym. J., 36, 2021-2030. http://dx.doi.org/10.1016/S0014-3057(99)00040-3

Lee, D. G. (1980). The oxidation of organic compounds by permanganate ion and hexavalent chromium. Open Court, La Salle, Illinois.

Lee, D. G., \& Brownridge, R. J. (1973). The oxidation of cinnamic acid by permanganate ion spectrophotometric detection of an intermediate. J. Am. Chem. Soc., 95, 3033-3034. http://dx.doi.org/10.1021/ja00790a060

Lee, D. G., \& Sebastian, C. F.(1981). The oxidation of phenol and chlorophenols by alkaline permanganate. Can. J. Chem., 59, 2776-2779. http://dx.doi.org/10.1139/v81-401

Manhas, M. S., Mohammed, F., \& Khan, Z. (2007). A kinetic study of oxidation of $\beta$-cyclodextrin by permanganate in aqueous media. Coll. Surf., 295, 165-171. http://dx.doi.org/10.1016/j.colsurfa.2006.08.048

Pretch, E., Clerc, T., Seibl, J., \& Simon, W. (1983). Tables of spectral data for structure determination of organic compounds. Berlin, Heidelberg, New York, Tokyo: Springer-Verlag http://dx.doi.org/10.1007/978-3-662-22455-7

Shaker, A. M. (2001a). Base catalyzed oxidation of carboxymethyl-cellulose Polymer by Permanganate. I-Kinetics and Mechanism of Formation of a manganate(VI) transient species complexes. J. Colloid Interface Sci., 233, 197-204. http://dx.doi.org/10.1006/jcis.2000.7246

Shaker, A. M. (2001b). Novel carboxymethyl cellulose ionotropic gels., II. Kinitecs of decomposition of the manganate(VI) intermediate-novel spectrophotometric tracer of the performed short lived hypomanganate(V) coordination polymer sol. J. Colloid Interface Sci., 244, $254-261$. http://dx.doi.org/10.1006/jcis.2001.7906

Shaker, A. M., El-Khatib, R. M., \& Mahran, H. S. (2007). Kinetics and mechanism of the decay of methyl cellulose manganate (VI) polysaccharide transient species novel spectrophotometric kinetic trace of methyl cellulose hypomanganate (V) gel intermediate. J. Appl. Polym. Sci., 106, 2668-2674. http://dx.doi.org/10.1002/app.26907

Simandi, L. I., Jaky, M., \& Schelly, Z. A. (1984). Short-lived manganate (VI) and hypomanganate (V) intermediates in the permanganate oxidation of sulfite. J. Am.Chem. Soc., 105, 3866-3867.

Stewart, R. (1965). Oxidation in organic chemistry. K. B. Wiberg (Ed.)., Part A., New York: Academic Press.

Stewart, R., \& Wiberg, K. B. (1965). Oxidation in organic chemistry (Vol.1). New York: Academic Press.

Wei, M. M., \& Stewart, R. (1966). The mechanism of permangante oxidation. VIII. Substituted benzylamines. J. Am. Chem. Soc., 88, 1974-1979. http://dx.doi.org/10.1021/ja00961a022

Zaafarany, I. A., Alarifi, A., Fawzy, A., Ahmed, G. A., Ibrahim, S. A., Hassan, R. M., \& Takagi, H. D. (2010). Further evidence for detection of short-lived transient hypomanganate (V) and manganate (VI) intermediates during oxidation of some sulfated polysaccharides by alkaline permanganate using conventional spectrophotometric techniques. Carbohydr. Res., 345, 1588-1593. http://dx.doi.org/10.1016/j.carres.2010.04.013

Zaafarany, I. A., Khairou, K. S., \& Hassan, R. M. (2010). Acid-catalysis of chromic acid oxidation of kappa-carrageenan polysaccharide in aqueous perchlorate solutions. J. Mol. Cat. A, 302, 112-118. http://dx.doi.org/10.1016/j.molcata.2008.12.005 


\section{Copyrights}

Copyright for this article is retained by the author(s), with first publication rights granted to the journal.

This is an open-access article distributed under the terms and conditions of the Creative Commons Attribution license (http://creativecommons.org/licenses/by/3.0/). 